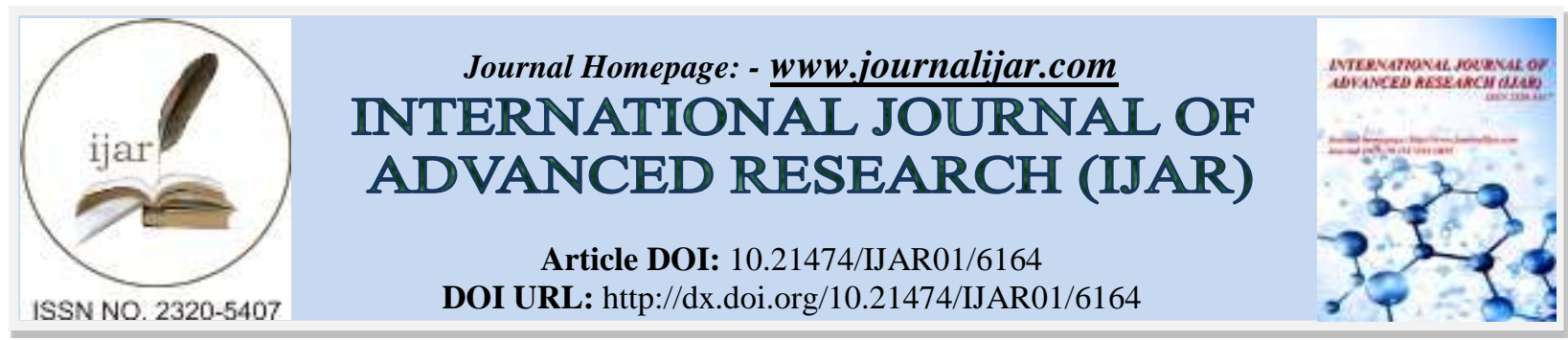

RESEARCH ARTICLE

\title{
HYPOVITAMINOSIS D DELETERIOUSLY AFFECT PREGNANCY OUTCOME: A PROPOSED ROLE FOR DAILY VITAMIN D SUPPLEMENTATION TO IMPROVE OUTCOME.
}

\author{
Mohamed Farag El Sherbeny MD ${ }^{1}$ and Raafat R. Mohammed MD $^{2}$.
}

1. Department of Obstetrics \& Gynecology, Faculty of Medicine, Benha University.

2. Follow \& Researcher of Medical Biochemistry, Hospital Lab., Clinical Pathology department, Faculty of Medicine, Benha University.

\section{Manuscript Info}

[.........................

Manuscript History

Received: 25 October 2017

Final Accepted: 27 November 2017

Published: December 2017

Keywords:-

Hypovitaminosis D, Vitamin D supplementation, Pregnancy, Maternal outcome, Fetal Outcome.

\section{Abstract}

Objectives: To estimate serum 25-hydroxy vitamin D (25OHD) levels in newly pregnant women and to evaluate its relation to development of gestational diabetes mellitus (GDM) and maternal and fetal outcome.

Patients \& Methods: The study included 328 pregnant women, and at $6^{\text {th }}$ week gestational age (GA), women's clinical and obstetric data were collected and blood samples were obtained for estimation of baseline blood glucose (BG) and serum 25OHD levels. Studied women were divided into two equal groups: Group A included pregnant women received supplemental vitamin D3 in a daily dose of 1000 IU oral capsule starting since $6^{\text {th }}$ week GA till delivery. Group B included pregnant women who completed their pregnancy without vitamin D supplementation. All women underwent the $75 \mathrm{~g}$ Oral Glucose Tolerance Test (75-OGTT) at the $20^{\text {th }}, 28^{\text {th }}$ and $36^{\text {th }}$ week for detection of GDM. All women were followed up till delivery and maternal and neonatal outcome.

Results: Serum 25OHD levels were sufficient, insufficient and deficient in 42, 142 and 144 women, respectively. Forty-three women (13.1\%) developed GDM and 62 women (18.9\%) had emergency and 23 women had elective CS. Moreover, 48 neonates (14.6\%) required NICU admission; 15 for respiratory-aid, 22 for phototherapy and 11 neonates for management of sepsis, but 4 neonates died. Women of group A showed significantly lower frequency of GDM with significantly lower BG levels, significantly lower frequency of CS especially emergency $\mathrm{CS}$ and significantly lower frequency of NICU admission.

Conclusion: Low serum 25OHD levels are a widespread problem among pregnant women and are associated with higher frequency of GDM, CS delivery especially emergency ones and NICU admission rate. Supplemental vitamin D therapy did well for reducing the frequencies of these events. Supplemental daily dose of 1000 IU appears appropriate and convenient as it was taken in the form of oral capsules.

Copy Right, IJAR, 2017,. All rights reserved. 


\section{Introduction:-}

Vitamin D is an important secosteroid hormone in skeletal and non-skeletal systems (Yoon, 2017). After absorption, vitamin $\mathrm{D}$ is bound to a binding protein which carries it in blood stream to the liver where vitamin D is hydroxylated into 25(OH) vitamin D (calcidiol), (Lapillonne, 2010) and then to the kidneys, where it is hydroxylated by CYP27B1 to 1,25 dihydroxy-vitamin D (calcitriol), which is the biologically active form of vitamin D (Cho et al., 2013).

Vitamin D receptors (VDR) are present in many non-skeletal tissues, so vitamin D via the binding to VDR can produce a number of desired biological effects via different mechanisms and, therefore, contributes to the improvement of human health (Teegarden \& Donkin, 2009).

However, accumulating evidence suggests that the metabolic pathways of vitamin D may play a key role in the development of gynecological/obstetric diseases (Colonese et al., 2015), such as polycystic ovary syndrome (VelijaAšimi, 2014), endometriosis (Sayegh et al., 2014), and ovarian and even breast cancer (Goodwin et al., 2009). Moreover, the maternal-fetal unit is under the influence of vitamin D, as a breakdown in its homeostasis may underlie infertility, preeclampsia, and gestational diabetes mellitus (Colonese et al., 2015).

Gestational diabetes mellitus (GDM) arises in women developed insufficient $\beta$-cell compensation for the insulin resistance of late pregnancy (Retnakaran et al., 2016). GDM is characterized by rising incidence, fostered by the worldwide increase of pathological nutritional status from young age (Triunfo et al., 2017).

The mechanisms underlying both normal antepartum $\beta$-cell adaptation and its aberrancy in GDM are unclear (Retnakaran et al., 2016). However, high maternal blood glucose (BG) levels during pregnancy induces adverse intrauterine environment, which has a negative impact on health outcomes for both the mother and the offspring (Silva-Zolezzi et al., 2017). On the other side, maternal vitamin D status is independently associated with markers of physiological and pathological growth in term infants (Gernand et al., 2012).

According to that previously documented by Wahlberg et al., (2016), each of vitamin D deficiency and GDM has been associated with increased risk of adverse perinatal outcomes, but the consequences of simultaneous presence of both conditions during pregnancy needs to be evaluated; thus, the current study aimed to estimate serum 25-hydroxy vitamin D (25OHD) levels in newly pregnant women and to evaluate its relation to development of GDM and maternal and fetal outcome.

\section{Setting:-}

Faculty of Medicine and University Hospital, Benha, Egypt

\section{Design:-}

Clinical prospective observational study

\section{Patients \& Methods:-}

The present study was started since Jan 2015 to July 2017. The study protocol was approved by the Local Ethical Committee and only women signed a written fully informed consent were included in the study. All pregnant women who attended the Antenatal Outpatient Clinic, at Benha University hospital for assurance of diagnosis of being pregnant were eligible for study inclusion. At $6^{\text {th }}$ week gestational age (GA), women's demographic and anthropometric data and previous clinical and obstetric data were collected. Body mass index (BMI) was calculated using the formula: weight $(\mathrm{kg}) /$ height $\left(\mathrm{m}^{2}\right)$ and patients were classified according to BMI using the World Health Organization ranges as underweight: $\mathrm{BMI}<18.5 \mathrm{~kg} / \mathrm{m}^{2}$, normal weight: $\mathrm{BMI}=18.5-24.9 \mathrm{~kg} / \mathrm{m}^{2}$, overweight: BMI $=25-29.9 \mathrm{~kg} / \mathrm{m}^{2}$ and obese: $\mathrm{BMI}=\geq 30 \mathrm{~kg} / \mathrm{m}^{2(14)}$.

At meantime, a random blood samples were obtained under complete aseptic conditions from the antecubital vein and divided into two parts:

1. The first part was put in a tube containing sodium fluoride ( $2 \mathrm{mg}$ sodium fluoride/ $\mathrm{ml}$ blood) to prevent glycolysis. Plasma was separated by centrifugation and used for estimation of fasting blood glucose (FBG) by glucose oxidase method (Tinder, 1969).

2. The second part was put in a plane container and left to clot at room temperature for 30 minutes before centrifugation for 20 minutes at $1,000 \mathrm{~g}$. Freshly prepared serum was stored at $-20^{\circ} \mathrm{C}$ till estimation of fasting serum 25-OHD levels using an ELISA kit (Cayman Chemical, Ann Arbor, MI, USA) (Andersen et al., 1993). 
Vitamin D sufficiency status was defined according to $25-\mathrm{OHD}$ concentration as follows: $\geq 75 \mathrm{nmol} / \mathrm{L}$ sufficient level, $50-75 \mathrm{nmol} / \mathrm{L}$ insufficient level and $<50 \mathrm{nmol} / \mathrm{L}$ deficient level. Vitamin D deficiency was categorized as mild, moderate and severe if 25-OHD concentration was $25-50 \mathrm{nmol} / \mathrm{L}, 12.5-25 \mathrm{nmol} / \mathrm{L}$ and $<12.5 \mathrm{nmol} / \mathrm{L}$, respectively (Stroud et al., 2008).

Women with current DM, history of previous GDM or obesity-inducing endocrinopathy, evident manifestations of hypo-parathyroidism, thyrotocixosis, renal or hepatic diseases and women lost during the course of pregnancy were excluded from the study.

After fulfilling the inclusion and exclusion criteria, enrolled women were randomly divided using sealed envelopes, prepared by an assistant blinded about the study plan, target for grouping and results of laboratory investigation, into two equal groups:

- Group A: included pregnant women assigned to received supplemental vitamin D3 according to Grant et al., (2014) in a daily oral dose of 1000 IU softgels to be taken with mail (Sunvite High Potency Vitamin D3 1000 IU; Puritan's Pride, Inc., Oakdale, NY, USA). Vitamin D supplementation started since $6^{\text {th }}$ week GA till delivery.

- Group B: included pregnant women who will complete their pregnancy without vitamin D supplementation.

All enrolled women were asked to fast and attend the antenatal care unit at the $20^{\text {th }}, 28^{\text {th }}$ and $36^{\text {th }}$ week GA. At time of each visit, all women underwent the $75 \mathrm{~g}$ Oral Glucose Tolerance Test (75-OGTT) which entails obtaining three blood samples an overnight fasting blood sample and then each woman was given an oral snake containing 75 gm glucose and another two blood samples were obtained at 1-hr and 2-hr postprandial (PP) for estimation of blood glucose. Women were categorized as having gestational diabetes mellitus (GDM) or not according to the criteria of the International Association of Diabetes and Pregnancy Groups (IADPSG, 2010) for abnormal OGTT, as follows: FBG $\geq 92 \mathrm{mg} / \mathrm{dl}, 1-\mathrm{h}$ BG $\geq 180 \mathrm{mg} / \mathrm{dl}$ and $2-\mathrm{h}$ BG $\geq 153 \mathrm{mg} / \mathrm{dl}$. All women were followed up till delivery and maternal and neonatal outcome were reported.

Statistical analysis:-

Obtained data were presented as mean $\pm \mathrm{SD}$, ranges, numbers and ratios. Results were analyzed using One-way ANOVA with post-hoc Tukey HSD test, and Chi-square test (X2 test). Statistical analysis was conducted using the SPSS (Version 15, 2006) for Windows statistical package. P value $<0.05$ was considered statistically significant.

\section{Results:-}

Throughout the duration of the study, 361 women were eligible for evaluation, 33 women were excluded and 328 women were included in the study (Fig. 1). Patients' demographic and clinical data and laboratory findings determined at time of $1^{\text {st }}$ antenatal visit showed non-significant $(\mathrm{p}>0.05)$ difference between both groups as shown in table 1 .

Table (1):- Patients' data determined at $1^{\text {st }}$ antenatal visit $\left(6^{\text {th }}\right.$ week GA)

\begin{tabular}{|c|c|c|c|c|}
\hline \multicolumn{2}{|l|}{ Data } & Group A $(n=164)$ & Group B $(n=164)$ & $\mathrm{P}$ value \\
\hline \multicolumn{2}{|l|}{ Age (years) } & $28.6 \pm 3.2$ & $28.3 \pm 2.9$ & 0.379 \\
\hline \multicolumn{2}{|l|}{ Weight (kg) } & $84.8 \pm 11$ & $86.8 \pm 12.2$ & 0.118 \\
\hline \multicolumn{2}{|l|}{ Height $(\mathrm{cm})$} & $168.7 \pm 3.3$ & $169.2 \pm 4.3$ & 0.213 \\
\hline \multicolumn{2}{|c|}{ Body mass index $\left(\mathrm{kg} / \mathrm{m}^{2}\right)$} & $29.8 \pm 4.1$ & $30.4 \pm 4.7$ & 0.259 \\
\hline \multicolumn{2}{|c|}{ Gravidity } & $2.4 \pm 1$ & $2.6 \pm 1.1$ & 0.051 \\
\hline \multicolumn{2}{|l|}{ Parity } & $1.2 \pm 0.9$ & $1.4 \pm 1.1$ & 0128 \\
\hline \multirow{2}{*}{$\begin{array}{l}\text { Laboratory } \\
\text { data }\end{array}$} & Fasting blood glucose & $81.6 \pm 11.2$ & $80.4 \pm 10.1$ & 0.302 \\
\hline & Serum 25-OHD & $48.7 \pm 22.8$ & $50.8 \pm 21.2$ & 0.393 \\
\hline
\end{tabular}

Data are presented as mean \pm SD \& numbers; percentages are in parenthesis; 25-OHD: 25-hydroxy vitamin D; p>0.05: indicates non-significant difference

Only 42 women (12.8\%) out of the total study population, had sufficient serum 25-OHD, 142 women (43.3\%) had insufficient serum level and 144 women (43.9\%) had deficient serum levels. Out of women had deficient 25-OHD serum level, 77 women $(23.5 \%)$ had mild deficiency, 49 women (14.9\%) had moderate deficiency and 18 women $(5.5 \%)$ had severe deficiency (Fig. 2). Patients' distribution according to extent of 25-OHD sufficiency showed non- 
significant ( $p>0.05)$ difference between studied groups among the main categories and categories of deficiency. Moreover, the differences between estimated levels showed non-significant $(p>0.05)$ difference between patients of both groups (Table 2, Fig. 3).

Table (2):- Patients' distribution according to serum 25-OHD estimated the $6^{\text {th }}$ week GA

\begin{tabular}{|c|c|c|c|c|c|}
\hline \multicolumn{3}{|l|}{ Data } & Group A $(n=164)$ & Group B (n=164) & $P$ value \\
\hline \multirow[t]{6}{*}{ Frequency } & \multicolumn{2}{|l|}{ Sufficient } & $19(11.6 \%)$ & $23(14 \%)$ & \multirow[t]{3}{*}{0.514} \\
\hline & \multicolumn{2}{|l|}{ Insufficient } & $68(41.5 \%)$ & $74(45.1 \%)$ & \\
\hline & \multicolumn{2}{|l|}{ Deficient } & $77(46.9 \%)$ & $67(40.9 \%)$ & \\
\hline & \multirow[t]{3}{*}{ Deficiency } & Mild & $36(22 \%)$ & $41(25 \%)$ & \multirow[t]{3}{*}{0.473} \\
\hline & & Moderate & $31(18.9 \%)$ & $18(11 \%)$ & \\
\hline & & Severe & $10(6 \%)$ & $8(4.9 \%)$ & \\
\hline \multirow[t]{6}{*}{ Levels (ng/ml) } & \multicolumn{2}{|l|}{ Sufficient } & $79.7 \pm 2.9$ & $78.3 \pm 2.4$ & 0.113 \\
\hline & \multicolumn{2}{|l|}{ Insufficient } & $65 \pm 7.5$ & $62.9 \pm 5.8$ & 0.069 \\
\hline & \multicolumn{2}{|l|}{ Deficient } & $26.6 \pm 9.6$ & $27.8 \pm 10.2$ & 0.465 \\
\hline & \multirow[t]{3}{*}{ Deficient } & Mild & $35.7 \pm 4$ & $34.8 \pm 5.7$ & 0.439 \\
\hline & & Moderate & $21.1 \pm 2.3$ & $19.7 \pm 2.8$ & 0.063 \\
\hline & & Severe & $11.1 \pm 0.9$ & $10.6 \pm 1.1$ & 0.313 \\
\hline
\end{tabular}

Data are presented as mean \pm SD \& numbers; percentages are in parenthesis; $p>0.05$ : indicates non-significant difference

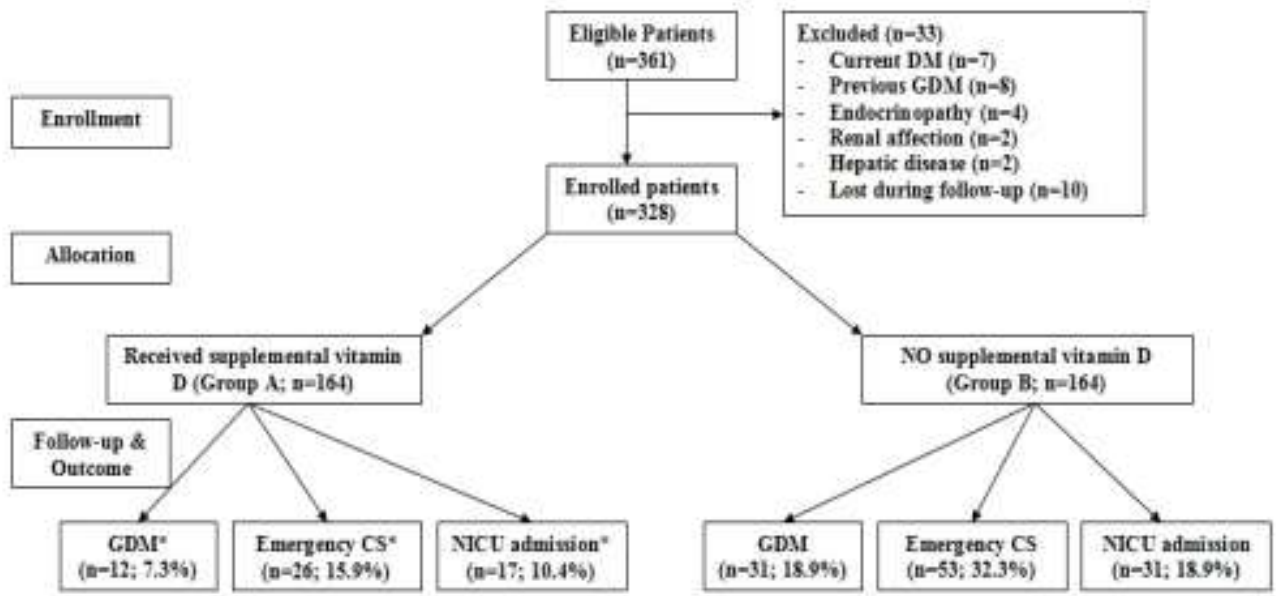

Fig. (1): Flow chart of the study (*: Significantly lower) 


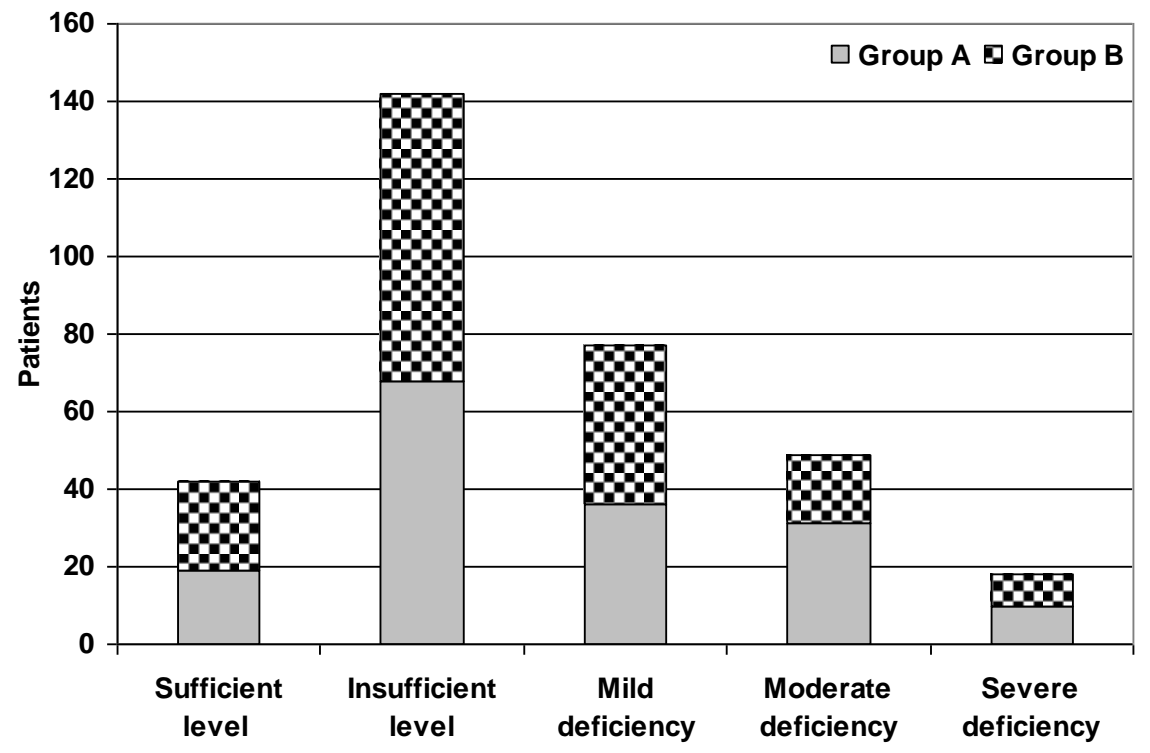

Fig. (2): Patients' distribution among sufficiency grades of vitamin $D$ as estimated at 1st antenatal visit

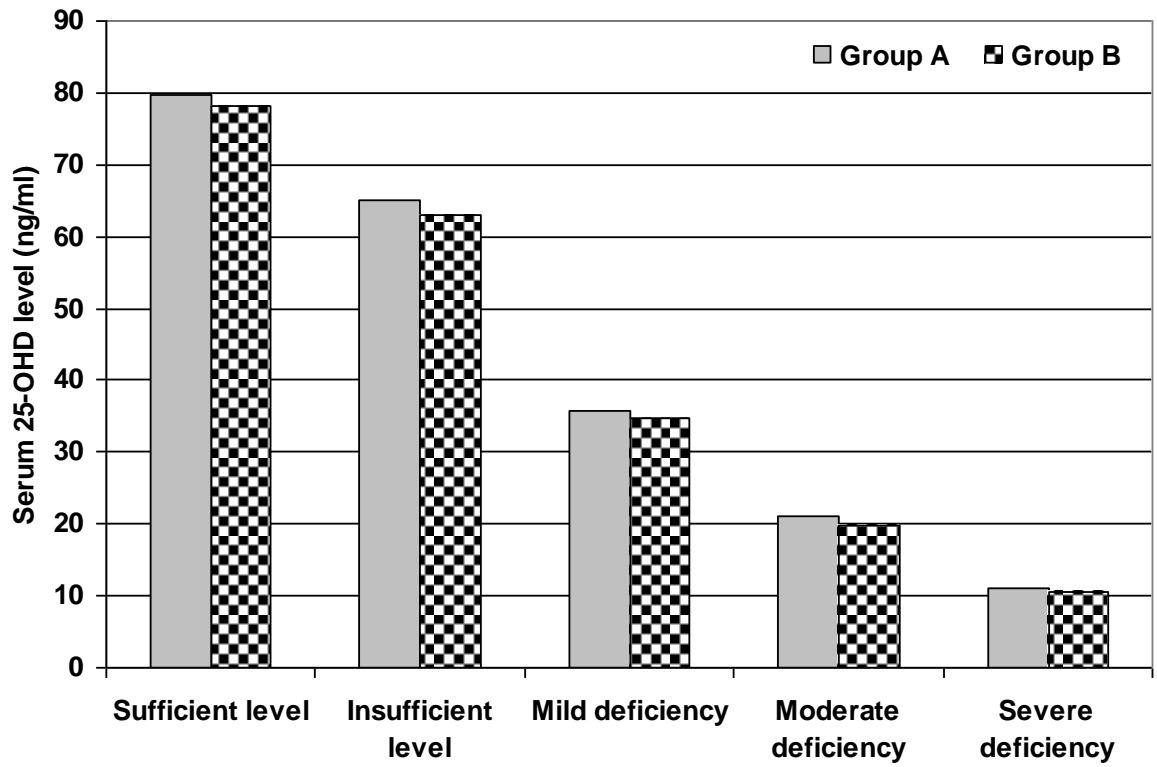

Fig. (3): Mean serum 25-OHD level estimated in studied women categorized according to vitamin $D$ sufficiency grade

Throughout the observation period, 43 women developed gestational diabetes mellitus (GDM) for a frequency of $13.1 \%$. Only, 12 of women received supplemental vitamin D therapy (Group A), while 31 of women did not receive supplemental vitamin D therapy (Group B) developed GDM with significantly $(\mathrm{p}=0.002)$ lower frequency of GDM among women of group A than group B. Time course development showed non-significantly ( $>0.05)$ lower frequency of women developed GDM among women of group A compared to women of group B at $20^{\text {th }}$ and $36^{\text {th }}$ week GA, while the frequency was significantly ( $\mathrm{p}=0.004$ ) lower at $28^{\text {th }}$ week GA (Fig. 4). Concerning blood glucose levels estimated during 75-OGTT, at the $20^{\text {th }}$ week GA, FBG and 2-hr PP blood glucose levels were nonsignificantly ( $>0.05)$ lower, while 1-hr PP blood glucose levels were significantly $(p=0.046)$ lower in women of group A than women of group B. At both $28^{\text {th }}$ and $36^{\text {th }}$ week GA, all of the three blood samples showed significantly lower blood glucose levels in women of group A compared to women of group B (Table 3). 
Table (3):- Patients' distribution according to the results of 75-OGTT performed throughout the observation period

\begin{tabular}{|c|c|c|c|c|c|c|}
\hline \multicolumn{4}{|l|}{ Data } & Group A $(n=164)$ & Group B $(n=164)$ & $\mathrm{P}$ value \\
\hline \multirow{8}{*}{$\begin{array}{l}\text { Frequency of patients } \\
\text { developed GDM } \\
\text { throughout observation } \\
\text { period }\end{array}$} & \multirow{2}{*}{\multicolumn{2}{|c|}{ At $20^{\text {th }}$ week GA }} & Yes & $4(2.4 \%)$ & $5(3 \%)$ & \multirow[t]{2}{*}{0.735} \\
\hline & & & No & $160(97.6 \%)$ & $159(97 \%)$ & \\
\hline & \multirow{2}{*}{\multicolumn{2}{|c|}{ At $28^{\text {th }}$ week GA }} & Yes & $6(3.7 \%)$ & $20(12.2 \%)$ & \multirow[t]{2}{*}{0.004} \\
\hline & & & No & $154(93.9 \%)$ & $139(84.8 \%)$ & \\
\hline & \multirow{2}{*}{\multicolumn{2}{|c|}{ At $36^{\text {th }}$ week GA }} & Yes & $2(1.2 \%)$ & $6(3.7 \%)$ & \multirow[t]{2}{*}{0.113} \\
\hline & & & No & $152(92.7 \%)$ & $133(81.1 \%)$ & \\
\hline & \multirow{2}{*}{\multicolumn{2}{|c|}{ Total }} & Yes & $12(7.3 \%)$ & $31(18.9 \%)$ & \multirow[t]{2}{*}{0.002} \\
\hline & & & No & $152(92.7 \%)$ & $133(3.7 \%)$ & \\
\hline \multirow{9}{*}{$\begin{array}{l}\text { Results of } 75 \text {-OGTT } \\
\text { determined throughout } \\
\text { observation period }\end{array}$} & \multirow{3}{*}{$\begin{array}{l}20^{\text {th }} \text { week } \\
\text { levels }\end{array}$} & \multicolumn{2}{|c|}{ FBG } & $82.8 \pm 7.7$ & $84.7 \pm 9.4$ & 0.064 \\
\hline & & \multicolumn{2}{|c|}{ 1-hr PP } & $160.6 \pm 14.3$ & $163.2 \pm 8.1$ & 0.046 \\
\hline & & \multicolumn{2}{|c|}{ 2-hr PP } & $122.7 \pm 7.8$ & $123.4 \pm 7.1$ & 0.057 \\
\hline & \multirow{3}{*}{$\begin{array}{l}28^{\text {th }} \text { week } \\
\text { levels }\end{array}$} & \multicolumn{2}{|c|}{ FBG } & $84.4 \pm 10.4$ & $88.9 \pm 13.9$ & 0.002 \\
\hline & & \multicolumn{2}{|c|}{ 1-hr PP } & $161.6 \pm 14.6$ & $168.4 \pm 22.8$ & 0.002 \\
\hline & & \multicolumn{2}{|c|}{ 2-hr PP } & $123.1 \pm 10.4$ & $127.1 \pm 15.9$ & 0.010 \\
\hline & \multirow{3}{*}{$\begin{array}{l}36^{\text {th }} \text { week } \\
\text { levels }\end{array}$} & \multicolumn{2}{|c|}{ FBG } & $86.1 \pm 11.8$ & $91.1 \pm 13.9$ & 0.001 \\
\hline & & \multicolumn{2}{|c|}{ 1-hr PP } & $165.6 \pm 14.6$ & $170.6 \pm 21.9$ & 0.012 \\
\hline & & \multicolumn{2}{|c|}{ 2-hr PP } & $124.1 \pm 11.6$ & $128.4 \pm 17.1$ & 0.009 \\
\hline
\end{tabular}

Data are presented as mean \pm SD \& numbers; percentages are in parenthesis; GDM: Gestational diabetes mellitus, GA: Gestational age; 75-OGTT: 75 gm oral glucose tolerance test; FBG: Fasting blood glucose; PP: Postprandial blood glucose; $\mathrm{p}<0.05$ : indicates significant difference; $\mathrm{p}>0.05$ : indicates non-significant difference

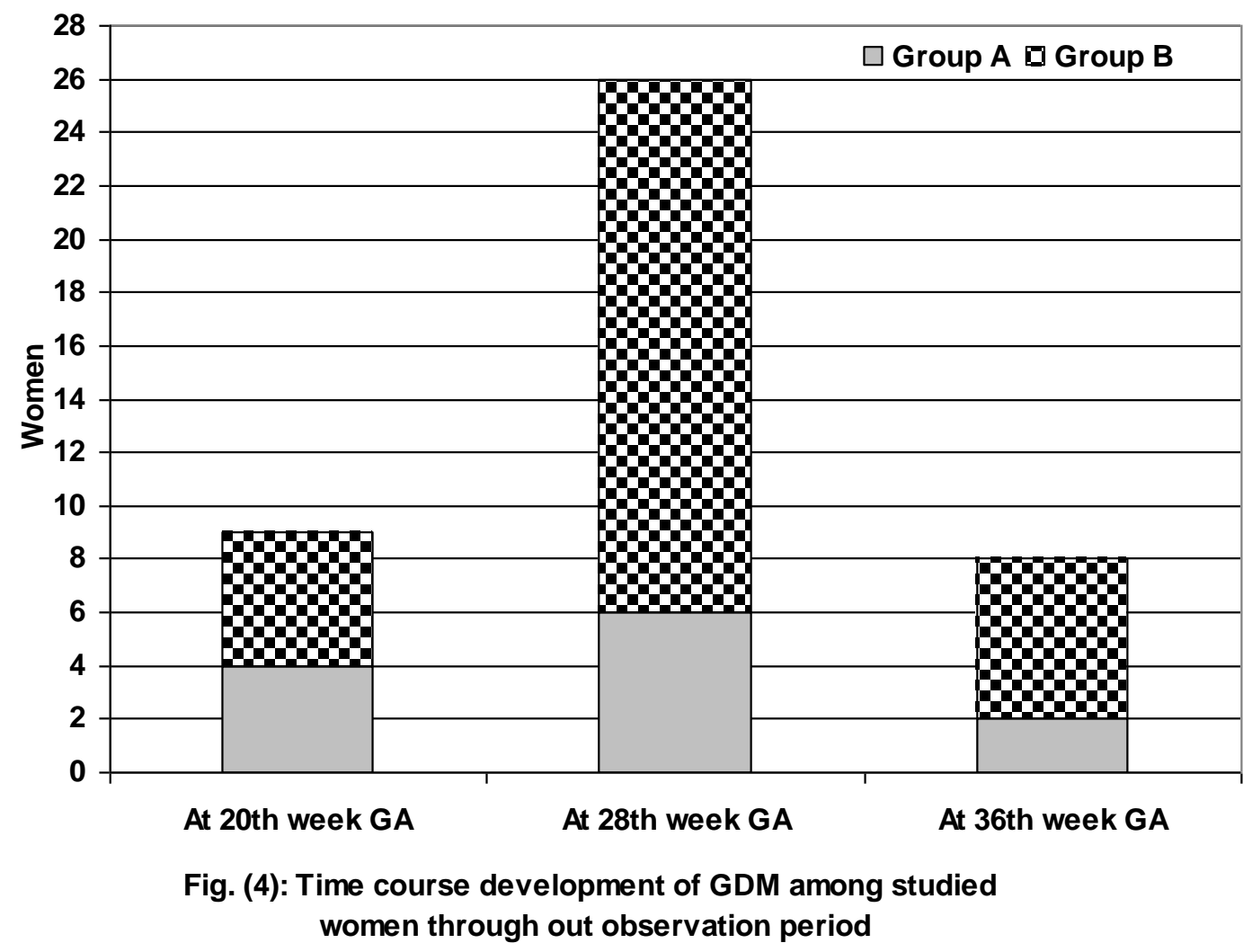


Eighty-five women (25.9\%) had cesarean section (CS); 34 in group A and 51 in group B with significantly $(p=0.032)$ lower frequency of CS among women of group A than in group B. Distribution of women had CS showed significance difference between women of both groups categorized according to extent of sufficiency of vitamin D levels $(\mathrm{p}=0.042)$ and according to development of GDM ( $\mathrm{p}=0.035)$ (Fig. 5). Sixty-two women (18.9\%) had emergency CS; 21 in group A and 41 in group B with significantly $(\mathrm{p}=0.041)$ lower frequency of emergency CS among women of group A than in group B. Distribution of women had emergency CS showed significance difference between women of both groups categorized according to extent of sufficiency of vitamin D levels $(\mathrm{p}=0.047)$ and non-significantly $(\mathrm{p}=0.097)$ according to development of GDM (Table 4).

Table (4):- Maternal outcome of studied women of both groups

\begin{tabular}{|c|c|c|c|c|c|c|}
\hline \multicolumn{3}{|l|}{ Outcome } & $\begin{array}{c}\text { Total } \\
(\mathrm{n}=328)\end{array}$ & $\begin{array}{c}\text { Group A } \\
(\mathrm{n}=164)\end{array}$ & $\begin{array}{c}\text { Group B } \\
(\mathrm{n}=164)\end{array}$ & $\begin{array}{c}\mathrm{P} \\
\text { value }\end{array}$ \\
\hline \multirow{2}{*}{$\begin{array}{l}\text { Mode of } \\
\text { delivery }\end{array}$} & \multicolumn{2}{|c|}{ Normal vaginal delivery } & $243(74.1 \%)$ & $130(79.3 \%)$ & $113(68.9 \%)$ & 0.032 \\
\hline & \multicolumn{2}{|l|}{$\mathrm{CS}$} & $85(25.9 \%)$ & $34(20.7 \%)$ & $51(31.1 \%)$ & \\
\hline \multirow{5}{*}{$\begin{array}{l}\text { Frequency of CS } \\
\text { according to } \\
\text { estimated levels } \\
\text { of }\end{array}$} & \multirow{3}{*}{$\begin{array}{l}\text { Serum } \\
25- \\
\text { OHD }\end{array}$} & Sufficient $(n=42)$ & $6(7 \%)$ & $2(5.9 \%)$ & $4(7.8 \%)$ & \multirow[t]{3}{*}{0.042} \\
\hline & & Insufficient $(\mathrm{n}=142)$ & $36(42.4 \%)$ & $20(58.8 \%)$ & $16(31.4 \%)$ & \\
\hline & & Deficient $(n=144)$ & $43(50.6 \%)$ & $12(35.3 \%)$ & $31(60.8 \%)$ & \\
\hline & \multirow[t]{2}{*}{ BG } & Normal $(n=285)$ & $68(80 \%)$ & $31(91.2 \%)$ & $37(72.5 \%)$ & \multirow[t]{2}{*}{0.035} \\
\hline & & GDM $(\mathrm{n}=43)$ & $17(20 \%)$ & $3(8.8 \%)$ & $14(27.5 \%)$ & \\
\hline \multirow[t]{2}{*}{ Type of CS } & \multicolumn{2}{|c|}{ Elective } & $23(27.1 \%)$ & $13(38.2 \%)$ & $10(19.6 \%)$ & \multirow[t]{2}{*}{0.041} \\
\hline & \multicolumn{2}{|c|}{ Emergency } & $62(72.9 \%)$ & $21(61.8 \%)$ & $41(80.4 \%)$ & \\
\hline \multirow{5}{*}{$\begin{array}{l}\text { Frequency of } \\
\text { emergency CS } \\
\text { according to } \\
\text { estimated levels } \\
\text { of }\end{array}$} & \multirow{3}{*}{$\begin{array}{l}\text { Serum } \\
25- \\
\text { OHD } \\
\end{array}$} & Sufficient $(\mathrm{n}=10)$ & $3(4.8 \%)$ & $1(4.8 \%)$ & $2(4.9 \%)$ & \multirow[t]{3}{*}{0.047} \\
\hline & & Insufficient $(\mathrm{n}=46)$ & $26(41.9 \%)$ & $12(57.1 \%)$ & $14(34.1 \%)$ & \\
\hline & & Deficient $(\mathrm{n}=53)$ & $33(53.3 \%)$ & $8(38.1 \%)$ & $25(61 \%)$ & \\
\hline & \multirow[t]{2}{*}{ BG } & Normal $(n=88)$ & $45(72.6 \%)$ & $18(85.7 \%)$ & $27(65.9 \%)$ & \multirow[t]{2}{*}{0.097} \\
\hline & & $\operatorname{GDM}(\mathrm{n}=21)$ & $17(27.4 \%)$ & $3(14.3 \%)$ & $14(34.1 \%)$ & \\
\hline
\end{tabular}

Data are presented as numbers \& mean \pm SD; percentages are in parenthesis; CS: Cesarean section; 25-OHD: 25hydroxy vitamin D; BG: Blood glucose; GDM: Gestational diabetes mellitus; $\mathrm{p}<0.05$ : indicates significant difference; $p>0.05$ : indicates non-significant difference

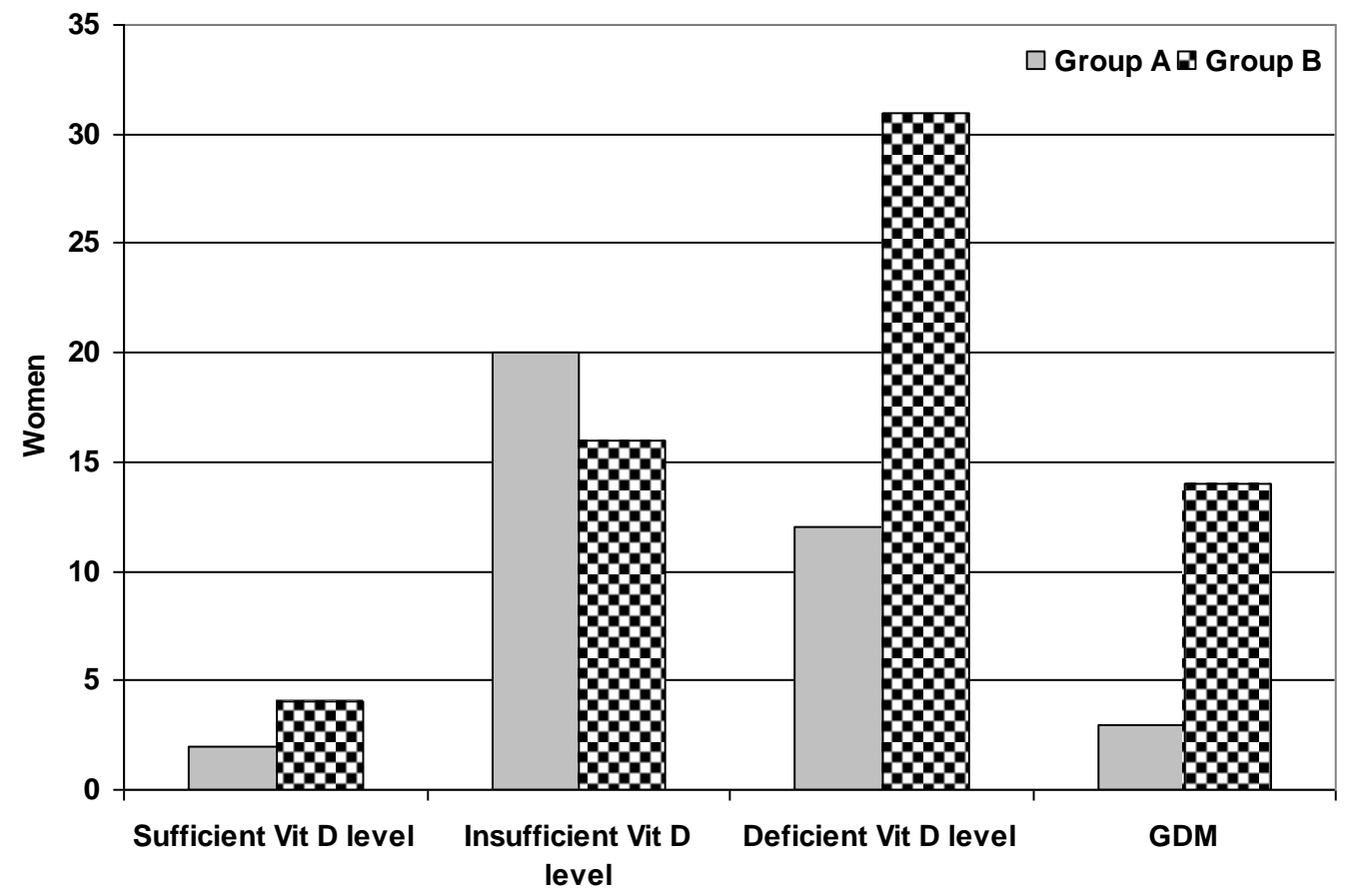

Fig. (5): Frequency of women had CS among studied women categorized according to vitamin D grades and development of GDM 
Mean APGAR score determined at 1-min and 5-min was significantly higher in neonates of group A than those of group B. Differentially according to the extent of vitamin D sufficiency, mean APGAR score was significantly higher in neonates of group A than in neonates of group B. Mean APGAR score of women categorized according to estimated blood glucose levels was significantly higher in neonates of group A than in group B. Forty-eight neonates $(14.6 \%)$ required NICU admission with significantly $(\mathrm{p}=0.029)$ lower frequency of NICU admission among neonates of group A compared to group B. Fifteen neonates required respiratory-aid and 22 required phototherapy management of hyperbilirubinemia with non-significantly higher frequencies among neonates of group B. Eleven neonates were NICU admitted for management of sepsis with significantly higher frequency among neonates of group B. Unfortunately, three neonates of group B and one of group A died with non-significant difference in favor of group A (Table 5).

Table (5):- Neonatal outcome of studied women of both groups

\begin{tabular}{|c|c|c|c|c|c|c|}
\hline \multicolumn{4}{|l|}{ Outcome } & $\begin{array}{l}\text { Group A } \\
(\mathrm{n}=164)\end{array}$ & $\begin{array}{l}\text { Group B } \\
(n=164)\end{array}$ & $\mathrm{P}$ value \\
\hline \multirow{5}{*}{ APGAR-1 } & \multirow{5}{*}{$\begin{array}{l}\text { according } \\
\text { to } \\
\text { estimated } \\
\text { levels of }\end{array}$} & \multirow{3}{*}{\begin{tabular}{|l} 
Serum \\
25-OHD
\end{tabular}} & Sufficient $(\mathrm{n}=42)$ & $7.9 \pm 1$ & $7.1 \pm 1.2$ & 0.070 \\
\hline & & & Insufficient $(\mathrm{n}=142)$ & $6.5 \pm 0.9$ & $6.3 \pm 0.8$ & 0.311 \\
\hline & & & Deficient $(n=144)$ & $6.2 \pm 0.8$ & $5.8 \pm 0.8$ & 0.001 \\
\hline & & \multirow[t]{2}{*}{ BG } & Normal $(\mathrm{n}=285)$ & $6.6 \pm 1$ & $6.4 \pm 1$ & 0.005 \\
\hline & & & GDM $(n=43)$ & $6.3 \pm 0.7$ & $5.5 \pm 0.8$ & 0.003 \\
\hline \multirow{5}{*}{ APGAR-5 } & \multirow{5}{*}{$\begin{array}{l}\text { according } \\
\text { to } \\
\text { estimated } \\
\text { levels of }\end{array}$} & \multirow{3}{*}{\begin{tabular}{|l|} 
Serum \\
25-OHD
\end{tabular}} & Sufficient $(n=42)$ & $8.9 \pm 0.8$ & $8 \pm 1.3$ & 0.005 \\
\hline & & & Insufficient $(\mathrm{n}=142)$ & $8.7 \pm 0.8$ & $7.4 \pm 1.4$ & 0.001 \\
\hline & & & Deficient $(n=144)$ & $8.6 \pm 0.6$ & $7.2 \pm 1.2$ & 0.001 \\
\hline & & \multirow[t]{2}{*}{ BG } & Normal $(\mathrm{n}=285)$ & $7.1 \pm 0.8$ & $6.8 \pm 0.7$ & 0.271 \\
\hline & & & GDM $(n=43)$ & $8.8 \pm 0.5$ & $7.5 \pm 1.4$ & 0.001 \\
\hline \multirow{2}{*}{\multicolumn{2}{|c|}{ NICU admission }} & \multicolumn{2}{|l|}{ Yes } & $17(10.4 \%)$ & $31(18.9 \%)$ & \multirow[t]{2}{*}{0.029} \\
\hline & & \multirow{2}{*}{\multicolumn{2}{|c|}{\begin{tabular}{|l} 
No \\
Ventilation
\end{tabular}}} & $147(89.6 \%)$ & $133(81.1 \%)$ & \\
\hline \multirow{3}{*}{\multicolumn{2}{|c|}{$\begin{array}{l}\text { Indication for NICU } \\
\text { admission }\end{array}$}} & & & $8(47.1 \%)$ & $10(32.3 \%)$ & 0.082 \\
\hline & & \multicolumn{2}{|c|}{ Phototherapy } & $7(41.2 \%)$ & $12(38.7 \%)$ & 0.727 \\
\hline & & \multicolumn{2}{|l|}{ Sepsis } & $2(11.8 \%)$ & $9(29 \%)$ & 0.037 \\
\hline \multicolumn{4}{|c|}{ NICU Mortality rate } & $1(5.9 \%)$ & $3(9.7 \%)$ & 0.649 \\
\hline
\end{tabular}

Data are presented as numbers \& mean \pm SD; percentages are in parenthesis; 25-OHD: 25-hydroxy vitamin D; BG: Blood glucose; GDM: Gestational diabetes mellitus; NICU: Neonatal ICU; $p<0.05$ : indicates significant difference; p>0.05: indicates non-significant difference

\section{Discussion:-}

Estimated serum 25OHD levels were insufficient in 142 women (43.3\%) and deficient in 144 women (43.9\%), while only 42 women had sufficient serum levels. This finding goes in hand with Loy et al., (2015) who reported a frequency of $25 \mathrm{ODH}$ inadequacy in $41.3 \%$ of their series of pregnant women. Thereafter, O'Callaghan-Gordo et al., (2017) documented that the prevalence of vitamin D deficiency is globally high. Both of Naseh et al. (2017) and Kilicaslan et al., (2017) reported that out of a sample population of pregnant women, no mother had sufficient vitamin D level, while $27 \%$ and $53 \%$ had vitamin D deficiency and $73 \%$ and $47 \%$ had vitamin D insufficiency. Furthermore, Wierzejska et al., (2017) documented that despite of higher maternal and umbilical cord blood concentrations of vitamin D in summer than in winter, only $16 \%$ of the pregnant women reached the optimal vitamin D concentration during summer.

Throughout the observation period, 43 women (13.1\%) developed GDM and 109 women (33.2\%) had CS; 62 women $(24.1 \%)$ had emergency and 23 women had elective CS. Moreover, 48 neonates $(14.6 \%)$ required NICU admission; 15 for respiratory-aid, 22 for phototherapy management and 11 neonates for management of sepsis, but unfortunately, 4 neonates died.

These data are in accordance with Lacroix et al., (2014) who reported that lower first trimester 25OHD levels were associated with higher risk of developing GDM and Jafarzadeh et al., (2015) who found a significant and inverse relationship between serum levels of 25OHD in the second trimester with insulin and 2-hr BG on 75-OGTT at 24-28 weeks GA. Thereafter, Lu et al., (2016) out of a meta-analysis included 20 observational studies containing 16,515 pregnant women documented that maternal vitamin D insufficiency is associated with increased risk of GDM. Also, 
Dodds et al., (2016) in a case-control study supported the inverse association of vitamin D status with GDM risk. Moreover, De-Regil et al., (2016) detected vitamin D adequacy, inadequacy and deficiency in 23, 39.5 and $37.5 \%$, respectively and found $7.5 \%$ of pregnant women developed preeclampsia, 6.5\% developed GDM. Also, Al-Shaikh et al., (2016) found $86.4 \%$ of their series of pregnant women had vitamin D deficiency and that GDM was the commonest complication which was detected in $11.1 \%$, while $24.5 \%$ of these women had history of miscarriage. Recently, Triunfo et al., (2017) reported that in pregnant women, lower 25OHD concentrations showed an inverse association with maternal glycaemia and increased risk of GDM.

The reported neonatal sequale of vitamin D status is in accordance with Weinert et al., (2016) who found newborns of women with vitamin D deficiency had higher incidences of ICU admission and of hypoglycemia. Ajmani et al., (2016) found that $9.5 \%$ of women with vitamin D deficiency delivered low-birth weight babies, $6 \%$ delivered premature babies and $8 \%$ of babies had APGAR score $<7$ at $5 \mathrm{~min}$, and $6 \%$ of babies were admitted in NICU. Bartáková et al., (2017) detected higher risk for adverse perinatal outcomes in women with low vitamin D levels.

Pregnant women included in group A, who had received supplemental vitamin D therapy since $6^{\text {th }}$ week GA till delivery in a daily dose of $1000 \mathrm{IU}$, showed significantly lower frequency of developing GDM with significantly lower blood glucose levels throughout the observation period in comparison to pregnant women who did not receive supplemental vitamin D therapy (Group B). Moreover, supplemental vitamin D therapy improved maternal and fetal outcome of women of group A that was manifested as significant reduction for the need for CS especially emergency CS with significantly lower frequency of newborns that required NICU admission. Interestingly, newborns of women of group A showed significantly lower frequency of NICU admission for septic indication, a finding indicating improvement of immunity of both the mother and the fetus that reflected as decreased frequency of neonatal sepsis.

In line with the use of supplemental vitamin D during pregnancy, Wierzejska et al., (2017) documented that despite improvement of vitamin D levels in summer, it does not guarantee that supplementation throughout the whole year is inessential. Moreover, Kiely et al., (2017) reported that estimated vitamin D metabolites in umbilical cord blood emphasize the high risk of very low vitamin D status in infants born to un-supplemented mothers.

The provided daily dose of supplemental vitamin D goes in hand with that previously documented in literature; where Cooper et al., (2016) found supplementation of women with cholecalciferol 1000 IU/day during pregnancy is sufficient to ensure that most pregnant women are vitamin D replete, and it is safe. Ceccaldi et al., (2017) documented that despite national guidelines on vitamin D supplementation, the rates are currently insufficient and the recommended 100,000 IU single dose helps to limit deficiency in newborns, but it fails to cover infant's needs for optimal status. Yilmaz et al., (2017) who documented that in order to be able to prevent neonatal vitamin D deficiency, $1200 \mathrm{IU} /$ day vitamin $\mathrm{D}$ was supplemented to mothers from the $12^{\text {th }}$ gestational week to $6^{\text {th }}$ month of the birth,

In support of the fetal benefit of maternal vitamin D supplementation, De-Regil et al., (2016) reported that data from three trials involving 477 women suggest that vitamin D supplementation during pregnancy reduces the risk preterm birth and increases infant length and head circumference at birth compared to no intervention or placebo and Kilicaslan et al., (2017) found that height; head circumference and chest circumference of newborns born to mothers who had received vitamin D support were significantly higher compared to non-receivers.

\section{Conclusion:-}

Low serum 25OHD levels are a widespread problem among pregnant women and are associated with higher frequency of GDM, CS delivery especially emergency ones and NICU admission rate. Supplemental vitamin D therapy did well for reducing the frequencies of these events. Supplemental daily dose of 1000 IU appears appropriate and convenient as it was taken in the form of oral capsules. However, wider scale studies are recommended to assure the benefit of vitamin D supplementation for other pregnancy-induced complications. 


\section{References:-}

1. Ajmani SN, Paul M, Chauhan P, Ajmani AK, Yadav N: Prevalence of Vitamin D Deficiency in Burka-clad Pregnant Women in a 450-Bedded Maternity Hospital of Delhi. J Obstet Gynaecol India. 2016;66(Suppl 1):6771.

2. Al-Shaikh GK, Ibrahim GH, Fayed AA, Al-Mandeel H: Impact of vitamin D deficiency on maternal and birth outcomes in the Saudi population: a cross-sectional study. BMC Pregnancy Childbirth. 2016; 16:119.

3. Andersen L, Dinesen B, Jørgensen PN, Poulsen F and Røder ME: Enzyme immunoassay for intact human insulin in serum or plasma. Clinical Chemistry, 1993; 38: 578-82.

4. Bartáková V, Tápalová V, Wágnerová K, Janků P, Bělobrádková J, Kaňková K: Pregnancy outcomes in women with gestational diabetes: specific subgroups might require increased attention. Ceska Gynekol. Winter 2017; 82(1):16-23.

5. Ceccaldi PF, Pejoan H, Breau N, Diallo D, Ducarme G, Poujade O, Davitian C, Luton D: French prenatal Vitamin D recommended supplementation: Enough or not? J Gynecol Obstet Hum Reprod. 2017; 46(1):35-41.

6. Cho GJ, Hong SC, Oh MJ, Kim HJ: Vitamin D deficiency in gestational diabetes mellitus and the role of the placenta. Am J Obstet Gynecol. 2013; 209(6):560.e1-8.

7. Colonese F, Laganà AS, Colonese E, Sofo V, Salmeri FM, Granese R, Triolo O: The pleiotropic effects of vitamin D in gynaecological and obstetric diseases: an overview on a hot topic. Biomed Res Int. 2015; 2015:986281.

8. Cooper C, Harvey NC, Bishop NJ, Kennedy S, Papageorghiou AT, Schoenmakers I, Fraser R, Gandhi SV, Carr A, D'Angelo S, Crozier SR, Moon RJ, Arden NK, Dennison EM, Godfrey KM, Inskip HM, Prentice A, Mughal MZ, Eastell R, Reid DM, Javaid MK; MAVIDOS Study Group: Maternal gestational vitamin D supplementation and offspring bone health (MAVIDOS): a multicentre, double-blind, randomised placebocontrolled trial. Lancet Diabetes Endocrinol. 2016; 4(5):393-402.

9. De-Regil LM, Palacios C, Lombardo LK, Peña-Rosas JP: Vitamin D supplementation for women during pregnancy. Sao Paulo Med J. 2016; 134(3):274-5.

10. Dodds L, Woolcott CG, Weiler H, Spencer A, Forest JC, Armson BA, Giguère Y: Vitamin D Status and Gestational Diabetes: Effect of Smoking Status during Pregnancy. Paediatr Perinat Epidemiol. 2016; 30(3):22937.

11. Goodwin PJ, Ennis M, Pritchard KI, Koo J, Hood N: Prognostic effects of 25-hydroxyvitamin D levels in early breast cancer. J Clin Oncol. 2009; 27(23):3757-63.

12. Grant CC, Stewart AW, Scragg R, Milne T, Rowden J, Ekeroma A, Wall C, Mitchell EA, Crengle S, Trenholme A, Crane J, Camargo CA Jr: Vitamin D during pregnancy and infancy and infant serum 25hydroxyvitamin D concentration. Pediatrics. 2014; 133(1):e143-53

13. International association of diabetes and pregnancy study groups (IADPSG) recommendations on the diagnosis and classification of hyperglycemia in pregnancy. Diabetes Care. 2010; 33:676-82.

14. Jafarzadeh L, Motamedi A, Behradmanesh M, Hashemi R: A comparison of serum levels of 25-hydroxy vitamin $\mathrm{d}$ in pregnant women at risk for gestational diabetes mellitus and women without risk factors. Mater Sociomed. 2015; 27(5):318-22.

15. Kiely M, O'Donovan SM, Kenny LC, Hourihane JO, Irvine AD, Murray DM: Vitamin D metabolite concentrations in umbilical cord blood serum and associations with clinical characteristics in a large prospective mother-infant cohort in Ireland. J Steroid Biochem Mol Biol. 2017; 167: 162-8.

16. Kilıcaslan AÖ, Kutlu R, Kilinc I, Ozberk DI: The effects of vitamin D supplementation during pregnancy and maternal vitamin D levels on neonatal vitamin D levels and birth parameters. J Matern Fetal Neonatal Med. 2017:1-8.

17. Lacroix M, Battista MC, Doyon M, Houde G, Ménard J, Ardilouze JL, Hivert MF, Perron P: Lower vitamin D levels at first trimester are associated with higher risk of developing gestational diabetes mellitus. Acta Diabetol. 2014; 51(4):609-16.

18. Lapillonne A: Vitamin D, deficiency during pregnancy may impair maternal and fetal outcomes. Med Hypotheses 2010, 74(1):71-5.

19. Loy SL, Lek N, Yap F, Soh SE, Padmapriya N, Tan KH, Biswas A, Yeo GS, Kwek K, Gluckman PD, Godfrey KM, Saw SM, Müller-Riemenschneider F, Chong YS, Chong MF, Chan JK; Growing Up in Singapore Towards Healthy Outcomes (GUSTO) study group: Association of Maternal Vitamin D Status with Glucose Tolerance and Caesarean Section in a Multi-Ethnic Asian Cohort: The Growing Up in Singapore Towards Healthy Outcomes Study. PLoS One. 2015; 10(11):e0142239.

20. Lu M, Xu Y, Lv L, Zhang M: Association between vitamin D status and the risk of gestational diabetes mellitus: a meta-analysis. Arch Gynecol Obstet. 2016; 293(5):959-66. 
21. Naseh A, Ashrafzadeh S, Rassi S: Prevalence of vitamin D deficiency in pregnant mothers in Tehran and investigating its association with serum glucose and insulin. J Matern Fetal Neonatal Med. 2017: 1-7.

22. O'Callaghan-Gordo C, Kogevinas M, Fthenou E, Pedersen M, Espinosa A, Chalkiadaki G, Daraki V, Dermitzaki E, Decordier I, Georgiou V, Merlo DF, Roumeliotaki T, Vande Loock K, Kleinjans J, KirschVolders M, Chatzi L: Vitamin D insufficient levels during pregnancy and micronuclei frequency in peripheral blood T lymphocytes mothers and newborns (Rhea cohort, Crete). Clin Nutr. 2017; 36(4):1029-35.

23. Retnakaran R, Ye C, Kramer CK, Connelly PW, Hanley AJ, Sermer M, Zinman B: Evaluation of Circulating Determinants of Beta-Cell Function in Women With and Without Gestational Diabetes. J Clin Endocrinol Metab. 2016; 101(7):2683-91.

24. Sayegh L, Fuleihan Gel-H, Nassar AH: Vitamin D in endometriosis: a causative or confounding factor? Metabolism. 2014; 63(1):32-41.

25. Silva-Zolezzi I, Samuel TM, Spieldenner J: Maternal nutrition: opportunities in the prevention of gestational diabetes. Nutr Rev. 2017 Jan;75(suppl 1):32-50.

26. Stroud ML, Stilgoe S, Stott VE, Alhabian O, Salman K: Vitamin D - a review. Aust Fam Physician. 2008; 37(12):1002-5.

27. Teegarden D, Donkin SS: Vitamin D: emerging new roles in insulin sensitivity. Nutr Res Rev. 2009; 22(1):8292.

28. Tinder P: Determination of blood glucose. Ann. Clin. Biochem.; 6:24, 1969.

29. Triunfo S, Lanzone A, Lindqvist PG: Low maternal circulating levels of vitamin D as potential determinant in the development of gestational diabetes mellitus. J Endocrinol Invest. 2017. doi: 10.1007/s40618-017-0696-9.

30. Velija-Ašimi Z: Evaluation of the association of vitamin D deficiency with gonadotropins and sex hormone in obese and non-obese women with polycystic ovary syndrome. Med Glas (Zenica). 2014; 11(1):170-6.

31. Wahlberg J, Ekman B, Nyström L, Hanson U, Persson B, Arnqvist HJ: Gestational diabetes: Glycaemic predictors for fetal macrosomia and maternal risk of future diabetes. Diabetes Res Clin Pract. 2016; 114:99-105.

32. Weinert LS, Reichelt AJ, Schmitt LR, Boff R, Oppermann ML, Camargo JL, Silveiro SP: Vitamin D Deficiency Increases the Risk of Adverse Neonatal Outcomes in Gestational Diabetes. PLoS One. 2016; 11(10):e0164999.

33. Wierzejska R, Jarosz M, Sawicki W, Bachanek M, Siuba-Strzelińska M: Vitamin D Concentration in Maternal and Umbilical Cord Blood by Season. Int J Environ Res Public Health. 2017; 14(10). pii: E1121.

34. Yılmaz B, Aygün C, Çetinoğlu E: Vitamin D levels in newborns and association with neonatal hypocalcemia. J Matern Fetal Neonatal Med. 2017:1-5.

35. Yoon HK: Gestational Diabetes Mellitus, Fetal Growth and Vitamin D. J Bone Metab. 2017;24(3):155-59. 